\title{
STS Interventions: Preparing, Defending, Learning
}

\author{
BRIAN MARTIN \\ University of Wollongong
}

\begin{abstract}
Intervening in the Australian vaccination debate, I found that STS perspectives helped me understand the controversy but gave little guidance on how to defend against attacks. Max Liboiron comments that preparation, including support networks, should precede interventions. I was well supported in my involvement in the vaccination debate, but those who openly advocate a stigmatized view may have difficulty gaining support. Teun Zuiderent-Jerak asks what is being learned when interventions reinforce existing categories. Controversy participants can learn by being exposed to STS perspectives; controversy researchers, when attacked, can gain new information and develop new research ideas.
\end{abstract}

\section{Keywords}

controversy; vaccination; intervention; preparation; support; learning

\section{Care and Solidarity}

In my paper "STS and Researcher Intervention Strategies" (Martin, 2016a), I described my experiences intervening in the Australian vaccination controversy. I found that STS perspectives were very useful for understanding the controversy but gave little guidance for what to do when I came under attack by partisans in the debate.

Max Liboiron (2016), in her comment on my paper, makes the excellent point that before undertaking interventionist STS research, preparation is vital. This includes building communities of care, so researchers can be personally supported if they come under attack, and building solidarity, so there exists the capacity for collective responses. Undoubtedly these are valuable, especially for those new to intervention research or who may be vulnerable to attack. Liboiron offers a rich set of ideas for learning about risky engagements and building solidarity networks, and I would recommend her advice and resources to anyone contemplating interventions in a controversial area. Liboiron goes a bit further and argues that calls for interventionist research shouldn't be made until adequate preparations have been made to support researchers.

I fully support Liboiron's argument about the importance of preparation. Because my aim in my article (Martin, 2016) was to highlight the lack of guidance from STS for crucial

\footnotetext{
${ }^{1}$ Brian Martin, Email: bmartin@uow.edu.au

Copyright (c) 2016 (Brian Martin). Licensed under the Creative Commons Attribution Non-commercial No Derivatives (by-nc-nd). Available at estsjournal.org.
} 
decisions while intervening, I did not address the issue of preparation, so it may be useful to make a few observations about my own experience.

When I set about intervening in the Australian vaccination controversy, I already had been studying and intervening in various scientific controversies for several decades, including being attacked by partisans (notably in the controversies over nuclear power and the origin of AIDS). Furthermore, by observing what was happening in the Australian vaccination debate, I had a good idea of the likely consequences of intervening, though perhaps not of the scale and viciousness of the response.

Throughout the numerous slurs on my reputation and complaints to my university, at no time have I felt distressed or unsupported. I do not take abusive comments personallyif anything, I find them amusing-but rather treat them as reflections on those who make them. Abusive comments and other means of trying to discredit or harass me are, for me, data that I can analyze. Indeed, they represent an unprecedented opportunity for me as a social researcher, the main challenge being a surfeit of material.

Furthermore, throughout the saga, I have been supported by nearly all of my immediate colleagues. Those who know me see me as a calm, committed, and methodical researcher. Whatever their views on vaccination, they can understand what I am trying to do. Furthermore, several of my colleagues (within STS and in related fields) themselves carry out research in controversial areas, and some have come under attack. In relation to criticisms of my research and supervision, the Vice-Chancellor and other senior administrators at the University of Wollongong have been very supportive of academic freedom. A dozen or so friends and colleagues, from within and outside the university, have independently inquired about how well I was holding up in the face of attacks. So I have been in a highly supportive environment. Others may not be so fortunate, and for them Liboiron's advice to undertake adequate preparation is crucial.

It is far easier to obtain support when one's position is backed by groups with public or academic credibility. A social researcher supportive of vaccination, if attacked, could call upon a huge and powerful support network. On the other hand, a social researcher openly critical of vaccination would have a much more restricted academic or professional support network. My own position—not having a strong view on vaccination—enabled me to tap support based on commitment to academic freedom.

Liboiron recommends that a climate scientist coming under public attack should contact the Union of Concerned Scientists for support—good advice indeed. But what about a climate skeptic coming under public attack? There is no obvious port of call. Contacting a fossil fuel company for assistance might only provide additional ammunition for attackers.

Liboiron implicitly assumes being attacked is undesirable, but there can be positive spinoffs. The recent campaign against my PhD student Judy Wilyman, me, and the University of Wollongong involved critical newspaper stories and a torrent of criticism and abuse on social media, among other things (Martin 2016b). However, most of those who directly contacted me were supportive, and they included individuals with inside information. I have gained insights and ideas for new research projects that otherwise would not have occurred.

${ }^{2}$ However, in practice only some academics support free inquiry when it is critical of vaccination. 
It is possible to imagine an intervention designed around a goal of stimulating publicity in order to gather information or research support. This has never been my intention but it is worth being aware of the possibility.

\section{Intervention Options}

The focus of my paper was defending against attacks. Teun Zuiderent-Jerak (2016) in his comment takes up the broader issue of options for STS intervention, certainly a topic well worth examining.

STS scholars and others can and do have multiple reasons for intervening in the issues they are studying. Zuiderent-Jerak emphasizes the goal of learning. He argues that when reinforcing the already existing assumptions about players and issues, there is little learning potential for the analyst (and perhaps not for the participants either). In the Australian vaccination controversy, the areas and modes of confrontation seemed to be well established, and by entering the controversy the way I did, on behalf of free speech, I might have been seen as reinforcing the battlelines.

This is not quite as I saw it, however. For decades, Australian vaccination proponents in government and the medical profession had introduced new vaccines and successfully encouraged a high level of coverage; infectious disease morbidity and mortality were very low. Relatively small numbers of citizen activists and groups, most prominent among them the Australian Vaccination Network (AVN), raised concerns about the effectiveness and risks of vaccination. During these years I knew about the controversy but saw no reason to intervene. Perhaps I should have.

What changed was the emergence of the group Stop the Australian Vaccination Network (SAVN) in 2009, dedicated to discrediting, silencing, and destroying the AVN and other vaccination critics. SAVN dramatically changed the dynamic of the debate from disagreements about vaccination to a struggle over whether it would be possible to openly question vaccination without being subject to personal abuse and attempted censorship. This was not something I had seen in such a stark form in any controversy I had studied, nor was it common in vaccination debates in other countries.

In my paper, I pointed out that STS provided little guidance for dealing with attacks. Zuiderent-Jerak says this is a request for detailed instructions about what to do, writing, "For if we were in the unique position of knowing exactly what to do, how would this then allow for the possibility of learning from intervening?" Actually, though, I was looking only for general principles for responding that I could apply to specific circumstances and decisions, analogous to my application of general STS insights to the Australian vaccination controversy.

Zuiderent-Jerak says that "Controversies, whether studied from 'top' or 'bottom', then come to consist of pre-given positions that the STS analysis further ossifies, repeats, reiterates, leaving those involved in the controversy with limited options: they either fight for or acquiesce to their marginalization." In seeking guidance about responding to attacks, I was indeed repeating a standard pattern in the Australian vaccination struggle: SAVN attacks the AVN, and the AVN defends; SAVN attacks me, and I defend. However, there are additional dimensions of intervention aside from defending against attack. One of them is the content of 
my writings. In several of my publications (Martin 2011, 2012, 2014), I offered insights from STS that could be used by participants to better understand scientific controversies. Furthermore, I offered strategic guidance that could be taken up by the AVN and alternative health practitioners who come under attack (Martin 2013). ${ }^{3}$ In addition, I have offered perspectives on the vaccination controversy- or example, suggestions for promoting children's health that both sides could agree on-that, if taken up, might provide a way of transcending the polarized confrontation (Martin, 2015: 333-334). My concern about obtaining guidance for defending against attack was thus in the context of enabling my continuing interventions that potentially destabilized the usual positions.

What researchers can do by intervening in the issue being studied depends a lot on their mindsets and skills. Zuiderent-Jerak's ideas for intervention, for example probing differences among partisans and possibly collaborating with some of them, are certainly worth consideration. There are multiple options in interventions. However, it is difficult for any individual to do several, so choices need to be made. In a highly polarized controversy, options are more limited. Zuiderent-Jerak suggests the possibility of collaborating with policy-makers or "doctors with critical ideas about pharma-push for vaccines." This would indeed be a stimulating possibility. However, anyone in the mainstream who steps out of line from vaccination orthodoxy in Australia risks coming under attack or being marginalized.

It would be highly stimulating if several social researchers intervened in a controversy and, following Zuiderent-Jerak's admonitions, pursued different approaches each intended to destabilize standard positions and to maximize insights about the controversy and about knowledge in the field. I think this is unlikely in the Australian vaccination controversy. There are numerous research possibilities, with ample data for analysis, but who else would want to jump into the fray?

\section{References}

Liboiron, M. 2016. "Care and Solidarity Are Conditions for Interventionist Research." Engaging Science, Technology, and Society 2: 67-72. DOI:10.17351/ests2016.85.

Martin, B. 2011. "Debating Vaccination: Understanding the Attack on the Australian Vaccination Network." Living Wisdom 8: 14-40.

Martin, B. 2012. "Online Onslaught: Internet-based Methods for Attacking and Defending Citizens' Organisations." First Monday: Peer-Reviewed Journal on the Internet 17 (12). Accessed February 5, 2016, http:/ / firstmonday.org/ojs/index.php/fm/article/view/4032/3379.

Martin, B. 2013. "Healthy Dissent: Resisting Attacks on Alternative Medicine." Townsend Letter 361-362 (August-September): 93-99.

Martin, B. 2014. The Controversy Manual. Sparsnäs, Sweden: Irene Publishing.

Martin, B. 2015. "A Vaccination Struggle." In Nonviolence Unbound, by B. Martin, 259-334. Sparsnäs, Sweden: Irene Publishing.

\footnotetext{
${ }^{3}$ My choice to publish my first piece (Martin 2011) in the AVN's magazine Living Wisdom might have reified the split between the sides, as Zuiderent-Jerak notes, but it increased the chance that AVN members would consider its STS analysis and insights about strategy.

' In practice, SAVNers have ignored my suggestions, while members of the AVN have discussed them but often continued on as usual.
} 
Martin, B. 2016a. "STS and Researcher Intervention Strategies." Engaging Science, Technology, and Society 2: 55-66. DOI:10.17351/ ests2016.15.

Martin, B. 2016b. "An Orchestrated Attack on a PhD Thesis." Accessed April 29, 2016. http:/ / comments.bmartin.cc/2016/02/01/an-orchestrated-attack-on-a-phd-thesis /

Zuiderent-Jerak, T. 2016. "If Intervention Is Method, What Are We Learning?" Engaging Science, Technology, and Society 2: 73-81. DOI:10.17351/ests2016.90. 